\title{
Lack of Influence of Serum Magnesium Levels on Overall Mortality and Cardiovascular Outcomes in Patients with Advanced Chronic Kidney Disease
}

\author{
Olimpia Ortega, Isabel Rodriguez, Gabriela Cobo, Julie Hinostroza, \\ Paloma Gallar, Carmen Mon, Milagros Ortiz, Juan Carlos Herrero, \\ Cristina Di Gioia, Aniana Oliet, and Ana Vigil \\ Nephrology Service, Hospital Severo Ochoa, Avenida Orellana s/n, Leganés 28911, Madrid, Spain \\ Correspondence should be addressed to Olimpia Ortega; oortega.hsvo@salud.madrid.org
}

Received 9 May 2013; Accepted 6 June 2013

Academic Editors: C. Escobar, C. Musso, D. G. Struijk, and Y. Takei

Copyright (c) 2013 Olimpia Ortega et al. This is an open access article distributed under the Creative Commons Attribution License, which permits unrestricted use, distribution, and reproduction in any medium, provided the original work is properly cited.

Background. Low serum magnesium has been associated with an increased cardiovascular risk in the general population and in dialysis patients. Our aim was to analyze the influence of serum magnesium on overall mortality and cardiovascular outcomes in patients with advanced CKD not yet on dialysis. Methods. Seventy patients with CKD stages 4 and 5 were included. After a single measurement of s-magnesium, patients were followed a mean of 11 months. Primary end-point was death of any cause, and secondary end-point was the occurrence of fatal or nonfatal CV events. Results. Basal s-magnesium was within normal range $(2.1 \pm 0.3 \mathrm{mg} / \mathrm{dL})$, was lower in men $(P=0.008)$ and in diabetic patients $(P=0.02)$, and was not different $(P=0.2)$ between patients with and without cardiopathy. Magnesium did not correlate with PTH, calcium, phosphate, albumin, inflammatory parameters (CRP), and cardiac (NT-proBNP) biomarkers but correlated inversely $(r=-0.23 ; P=0.052)$ with the daily dose of loop diuretics. In univariate and multivariate Cox proportional hazard models, magnesium was not an independent predictor for overall mortality or CV events. Conclusions. Our results do not support that serum magnesium can be an independent predictor for overall mortality or future cardiovascular events among patients with advanced CKD not yet on dialysis.

\section{Introduction}

Magnesium is predominantly an intracellular cation. Serum magnesium concentration does not reflect total body magnesium content since $60 \%$ is found in the skeleton, $39 \%$ intracellular and only $1 \%$ extracellular [1].

Magnesium $(\mathrm{Mg})$ plays an important role in the regulation of vascular tone and heart rhythm $[2,3]$. Magnesium deficiency has been reported to promote inflammation, and it decreases the specific immune response [4]. Magnesium also reduces total peripheral resistance by stimulation of nitric oxide synthesis [5] and is a potent inhibitor of vascular calcification [6-8].

In the general population, it seems that hypomagnesaemia may play a significant role in the development of cardiovascular disease $[9,10]$.

The gastrointestinal tract, the skeleton, and the kidneys are integrally involved in normal magnesium homeostasis.
Renal failure is the most common cause of hypermagnesemia, which is usually mild and asymptomatic. In CKD, when GFR falls to below $30 \mathrm{~mL} / \mathrm{min}$, urinary $\mathrm{Mg}$ excretion may be insufficient to balance intestinal $\mathrm{Mg}$ absorption leading to chronic Mg overload [11]. However, some conditions can lead to negative $\mathrm{Mg}$ balance even in these patients, such as excessive intake of diuretics, reduced gastrointestinal intake, and a low $\mathrm{Mg}$ concentration of dialysate $[12,13]$.

Cardiovascular disease is the leading cause of mortality and morbidity in patients with CKD. Several traditional and nontraditional risk factors have been identified as risk factors for the increased mortality of end-stage renal disease patients. Accelerated atherosclerosis associated with vascular calcification of intima and media layers and arterial stiffening is a frequent finding in these patients [14] and is a strong risk factor for increased morbidity and mortality $[15,16]$. In hemodialysis patients, an inverse association between serum 
$\mathrm{Mg}$ and the common carotid intima-media thickness has been observed [17, 18], and some recent observational studies have confirmed the superior survival of dialysis patients with serum $\mathrm{Mg}$ levels above the normal range [19]. This survival advantage could be related to the inhibition of vascular calcification, phosphate-lowering effect, and to the reduction of the oxidative stress [20-22].

The aim of our study was to evaluate whether serum $\mathrm{Mg}$ level could be an independent predictor of mortality and future cardiovascular events even in patients with advanced renal failure not yet on dialysis.

\section{Patients and Methods}

All of the seventy patients with stages 4 and 5 CKD followed in our predialysis out-patient unit were included in the study. Mean age was $64 \pm 13$ years (32-87 years), and 46 patients $(66 \%)$ were men. Median follow-up in our predialysis unit prior the inclusion in the study was 2 years (interquartile range: $0.9-3$ years). Clearance of creatinine $(\mathrm{CrC})$ was calculated using the 24-hour collection method. Mean $\mathrm{CrC}$ at the start was $20 \pm 7 \mathrm{~mL} / \mathrm{min}$. No patient received magnesium supplements during the study.

After a single measurement of serum Mg level, patients were followed-up for time-to-event analysis until the occurrence of death or cardiovascular event. Primary end-point was all-cause mortality, and secondary end-point was fatal or nonfatal CV events. Cardiovascular events were defined as myocardial infarction, angina, sudden death of cardiac origin, heart failure episode, stroke, or complicated peripheral vascular disease. Patients who initiate dialysis during the follow-up period were followed until death, occurrence of $\mathrm{CV}$ events, or until the end of the study and were not censored at initiation of renal replacement therapy.

All blood samples were obtained from patients in the morning after 12 hours of fasting for measurement of the biochemical data. Besides Mg levels, biochemical data recorded included serum calcium, phosphate, alkaline phosphatase, $\mathrm{PTH}$, levels of $\mathrm{OH}$-vitamin $\mathrm{D}$, blood $\mathrm{Hb}$, serum albumin, transferrin, cholesterol, 24-hours proteinuria, CRP levels, and levels of NT-proBNP.

Serum CRP was measured by nephelometry on a BNA II (Dada Behring, Liederbach, Germany). NT-pro BNP was determined using chemiluminiscent Elecsys proBNP sandwich immunoassay (ECLIA) on an Elecsys 2010 (Roche Diagnostic, Mannheim, Germany). The levels of 25-OHvitamin $\mathrm{D}$ were determined by radioimmunoassay (Dia Sorin, Stillwater, Minn, USA).

The use of erythropoiesis stimulating agents and the weekly dose employed were included in the study as well as the use of vitamin D supplements. The dose of loop diuretics was also recorded, as most of our predialysis patients used diuretics as part of our strategy of strict volume control in combination with a low sodium diet prescription.

All the statistical analyses were performed by using SPSS 11.0 (SPSS Inc., Chicago, Ill, USA) statistical package. Nonnormally distributed variables were expressed as median (range), and normally distributed variables were as mean
TABLE 1: Demographic characteristics of the population studied.

\begin{tabular}{lc}
\hline Age (years) & $64 \pm 13^{*}$ \\
Sex (men) & $46(66)$ \\
Causes of CKD & \\
$\quad$ Diabetes & $23(34)$ \\
Vascular & $18(26)$ \\
Chronic glomerulonephritis & $16(23)$ \\
Interstitial & $4(6)$ \\
PQKD & $2(3)$ \\
Unknown & $4(6)$ \\
Other nephropaties & $1(2)$ \\
CKD stages & \\
Stage 4 (\%) & $47(67)$ \\
Stage 5 (\%) & $23(33)$ \\
Vintage in predialysis (years) & $2(0.9-3)^{\dagger}$ \\
Associated cardiopathy & $22(32)$ \\
Peripheral vascular disease & $10(14)$ \\
\hline
\end{tabular}

Data expressed as number (percentage), ${ }^{*}$ mean $\pm \mathrm{SD}$ or ${ }^{\dagger}$ median (interquartile range). CKD: chronic kidney disease; $\mathrm{PQKD}$ : polycystic kidney disease.

$\pm \mathrm{SD}$, as appropriate. A " $P$ " value $<0.05$ was considered to be statistically significant. Pearson or Spearman coefficients were used to determine correlations between continuous variables. Survival and time-to-event analysis were done using the Cox proportional hazards model, including adjustment for potential confounding factors. Data are presented in the form of hazard ratios (HR) and 95\% CI.

\section{Results}

Demographic characteristics of the population studied are expressed in Table 1. As the population includes relatively old patients, vascular and diabetic nephropathy are the most frequent causes of CKD. The 47 patients with CKD stage 4 had a mean $\mathrm{CrC}$ of $24 \pm 5 \mathrm{~mL} / \mathrm{min}$ whereas mean $\mathrm{CrC}$ in patients with CKD stage 5 was $12 \pm 4 \mathrm{~mL} / \mathrm{min}$. The prevalence of cardiovascular disease was elevated in the population studied. Thirty-two percent of the patients had associated cardiopathy, defined as presence of valvular cardiopathy, hypertrophic cardiopathy, previous heart failure episodes, arrhythmias, or ischemic cardiopathy. Ischemic cardiopathy was present in 17 patients representing the most frequent cause of associated cardiopathy. Peripheral vascular disease was also frequent in this population (14\%).

Table 2 expresses the biochemical parameters at baseline. Mean serum $\mathrm{Mg}$ level was within normal range in our patients $(2.1 \pm 0.4 \mathrm{mg} / \mathrm{dL}$; normal range: $1.58-2.55 \mathrm{mg} / \mathrm{dL})$ without significant differences between patients with CKD stages 4 and $5(2.1 \pm 0.3 \mathrm{mg} / \mathrm{dL}$ in stage 4 versus $2.2 \pm$ $0.3 \mathrm{mg} / \mathrm{dL}$ in stage $5 ; P=0.25$ ).

Serum $\mathrm{Mg}$ was significantly lower in men $(2.04 \pm$ $0.3 \mathrm{mg} / \mathrm{dL}$ versus $2.26 \pm 0.3 \mathrm{mg} / \mathrm{dL}$ in women; $P=0.008)$ and in diabetic patients $(1.98 \pm 0.3 \mathrm{mg} / \mathrm{dL}$ versus $2.2 \pm 0.3 \mathrm{in}$ non-diabetic patients; $P=0.02$ ). We found no significant differences in serum $\mathrm{Mg}$ levels between patients with and without clinical evident cardiopathy $(P=0.22)$. Patients 
TABLE 2: Biochemical data at baseline of the population studied.

\begin{tabular}{lc}
\hline CrC (mL/min) & $20 \pm 7$ \\
Magnesium (mg/dL) & $2.1 \pm 0.4$ \\
Calcium (mg/dL) & $9.3 \pm 0.6$ \\
Phosphate (mg/dL) & $4.2 \pm 0.9$ \\
Alkaline phosphatase (IU/L) & $96 \pm 38$ \\
PTH (pg/mL) & $302 \pm 239$ \\
25 OH vitamin D (ng/mL) & $16 \pm 11$ \\
Albumin (g/dL) & $4.1 \pm 0.4$ \\
Transferrin (mg/dL) & $214 \pm 38$ \\
Cholesterol (mg/dL) & $176 \pm 39$ \\
Proteinuria (g/24 h) & $0.8(0.4-2.2)$ \\
Hemoglobin (g/dL) & $12.6 \pm 1.6$ \\
CRP (mg/L) & $4(1.8-11)$ \\
NT-proBNP (pg/mL) & $626(251-1567)$ \\
\hline
\end{tabular}

Data expressed as mean \pm SD or median (interquartile range).

CrC: clearance of creatinine; PTH: parathyroid hormone; CRP: C-reactive protein.

with and without peripheral vascular disease showed also no statistically different $\mathrm{Mg}$ levels $(P=0.48)$.

At baseline, serum Mg did not correlate with patient's age $(P=0.35)$. We found no significant correlation between serum $\mathrm{Mg}$ and bone and mineral metabolism parameters; there was no significant relationship between serum $\mathrm{Mg}$ and serum calcium $(P=0.76)$, phosphate $(P=0.65)$, alkaline phosphatase $(P=0.8)$, PTH $(P=0.4)$, or $25 \mathrm{OH}$ vitamin $\mathrm{D}$ levels $(P=0.14)$. There were also no differences in Mg levels between patients with or without vitamin D supplements (2.1 $\pm 0.8 \mathrm{mg} / \mathrm{dL}$ in patients with vitamin $\mathrm{D}$ supplements versus $2.2 \pm 0.3 \mathrm{mg} / \mathrm{dL}$ in patients without vitamin $\mathrm{D} ; P=0.25$ ).

Serum $\mathrm{Mg}$ did not correlate either with nutritional parameters at baseline; there was no significant correlation with serum albumin $(P=0.53)$, transferrin $(P=0.21)$, or cholesterol $(P=0.51)$. The relationship with cardiac and inflammatory parameters was also not significant $(P=0.7$ with NT-proBNP; $P=0.16$ with CRP levels). We found no significant correlation between serum $\mathrm{Mg}$ and blood hemoglobin $(P=0.4)$ as well as with the weekly dose of erythropoietin $(P=0.94)$. On the contrary, serum $\mathrm{Mg}$ correlated inversely with the daily dose of loop diuretics, although the correlation did not achieve statistical significance $(r=-0.23$; $P=0.052$ ).

During the follow-up period, 6 patients (9\%) died, in 11 patients (17\%) a fatal or nonfatal CV event occurred, and 13 patients (20\%) started renal replacement therapy. These patients were followed until death, the development of $\mathrm{CV}$ event, or until the end of the study; thus, patients who started dialysis were not censored at the initiation of dialysis.

The mean follow-up period was $11 \pm 2.8$ (range 4-15) months. Primary end-point was all-cause mortality, and secondary end-point was the development of fatal or nonfatal $\mathrm{CV}$ event. The predictors for time to-death and time toCV events were studied by univariate and multivariate Cox regression analysis. Serum $\mathrm{Mg}$ does not predict death for all causes and was not an independent predictor of fatal or nonfatal CV event neither in univariate nor in multivariate analysis. Figure 1 shows the Kaplan-Meyer curves of allcause mortality according to median serum magnesium levels $(<2.1 \mathrm{mg} / \mathrm{dL}$ or $\geq 2.1 \mathrm{mg} / \mathrm{dL})$; there were no significant differences in both survival curves $(P=0.97$ by the log-rank test). Figure 2 expresses the development of fatal or nonfatal $\mathrm{CV}$ event according to median magnesium levels; there was also no significant differences between the two curves $(P=$ 0.35 by the log-rank test).

In univariate Cox regression, patient's age, the presence of peripheral vascular disease, serum albumin, and C-reactive protein and creatinine clearance were independent predictors of all-cause mortality (Table 3). In a forward conditional multivariate Cox regression analysis, the factors which significantly contributed to predicting outcome independent of each other and confounders were CRP (HR 1.1; CI: 1.03-1.12; $P=0.04)$, the presence of peripheral vascular disease (HR 18.6; CI 1.9-180; $P=0.01$ ), and serum albumin (HR 0.06; CI $0.005-0.77 ; P=0.03$ ). Of note is that serum magnesium does not influence on all-cause mortality either in univariate or in multivariate Cox regression analysis.

The independent predictors of the development of fatal or nonfatal CV events in univariate analysis are expressed in Table 4. Previous history of cardiopathy, peripheral vascular disease, diabetes, serum albumin and transferrin were independent predictors of future CV events. The influence of 24hour proteinuria was in the limit of statistical signification $(P=0.06)$ in univariate analysis. The multivariate stepwise forward conditional Cox regression analysis shows that only peripheral vascular disease (HR 22.7; CI 2.7-190; $P<0.005$ ) and 24-hour proteinuria (HR 1.5; CI 1.12-2.2; $P<0.01$ ) are independent predictors of CV events after adjustment for confounders. Newly, serum magnesium did not influence on $\mathrm{CV}$ events neither in univariate nor in multivariate Cox regression analysis.

\section{Discussion}

The main finding of our study is that serum magnesium level does not seem to be an independent predictor of overall mortality or future cardiovascular events among patients with advanced CKD not yet on dialysis, at least at short-term followup. Serum magnesium level also does not correlate with bone and mineral metabolism parameters in our predialysis patients.

Our results are not consistent with those observed by other authors who suggest a survival advantage in patients with slightly elevated serum magnesium concentration. In hemodialysis patients, some authors [19] have found that mortality rates were significantly higher in the group with lower baseline magnesium levels and that serum magnesium levels were a significant and independent predictor of overall mortality but not for death from cardiovascular causes. More recently, Kanbay and colleagues [22] evaluated the possible contribution of magnesium on cardiovascular outcome in patients with moderate-to-severe CKD not yet on dialysis. They found that serum magnesium may be an independent predictor of future cardiovascular outcomes. Compared to 


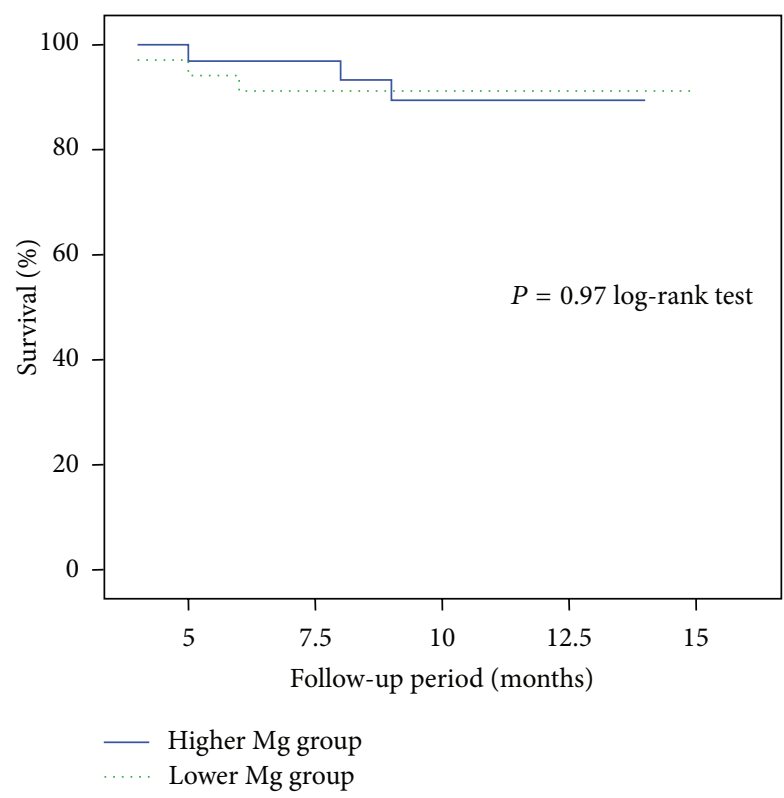

FIGURE 1: Kaplan-Meier survival curves according to median serum magnesium levels $(<2.1 \mathrm{mg} / \mathrm{dL}$ or $\geq 2.1 \mathrm{mg} / \mathrm{dL})$.

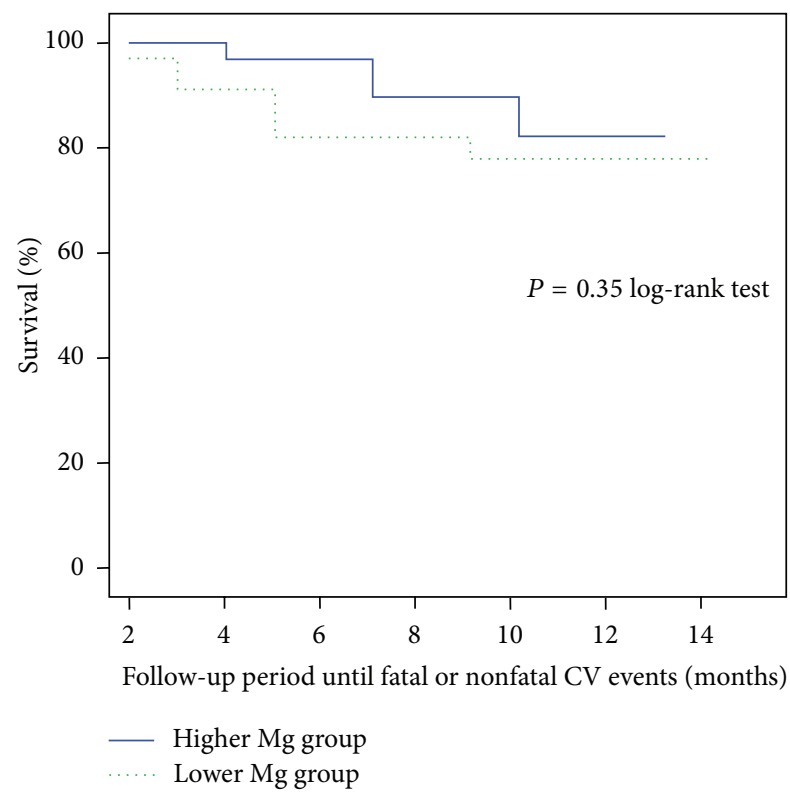

Figure 2: Kaplan-Meier development of fatal and nonfatal cardiovascular events curves according to median serum magnesium levels $(<2.1 \mathrm{mg} / \mathrm{dL}$ or $\geq 2.1 \mathrm{mg} / \mathrm{dL})$.

our study, Kanbay and colleagues included patients with a wider range of creatinine clearance as there were a high proportion of patients with stage $3 \mathrm{CKD}$, no patients received diuretics, and finally mean follow-up period was longer than in our study. Unlike the Kanbay's study, most of our predialysis patients used loop diuretics at different doses as part of our strategy of strict volume control, which consists of a prescription of low sodium diet and the rational use of loop diuretics in order to achieve adequate blood
TABLE 3: Independent predictors of overall mortality. Univariate Cox analysis.

\begin{tabular}{lccc}
\hline & HR & $95 \%$ CI & $P$ \\
\hline Age (years) & 1.13 & $1.02-1.24$ & $\mathbf{0 . 0 2 1}$ \\
Diabetes (yes/no) & 3.71 & $0.7-20.6$ & n.s \\
Cardiopathy (yes/no) & 1.6 & $0.27-9.6$ & n.s. \\
Peripheral vasc. dis. (yes/no) & 14.1 & $1.6-121$ & $\mathbf{0 . 0 1 6}$ \\
\hline Mg (mg/dL) & 1.5 & $0.15-14.7$ & n.s \\
Calcium (mg/dL) & 0.4 & $0.12-1.5$ & n.s \\
Phosphate (mg/dL) & 1.04 & $0.43-2.5$ & n.s \\
PTH (pg/mL) & 0.99 & $0.99-1.003$ & n.s \\
25 OH vitamin D (ng/mL) & 0.79 & $0.59-1.06$ & n.s \\
\hline Albumin (g/dL) & 0.098 & $0.02-0.44$ & $\mathbf{0 . 0 0 2}$ \\
Transferrin (mg/dL) & 0.98 & $0.96-1.003$ & n.s \\
Proteinuria (g/24 h) & 1.07 & $0.79-1.01$ & n.s \\
CrC (mL/min) & 0.8 & $0.7-0.97$ & $\mathbf{0 . 0 2}$ \\
Hemoglobin (g/dL) & 0.59 & $0.34-1.05$ & n.s \\
CRP (mg/L) & 1.1 & $1.03-1.18$ & $\mathbf{0 . 0 3}$ \\
\hline
\end{tabular}

TABLE 4: Independent predictors of fatal and non fatal cardiovascular events. Univariate Cox analysis.

\begin{tabular}{lccc}
\hline & HR & $95 \%$ CI & $P$ \\
\hline Age (years) & 1.03 & $0.99-1.08$ & n.s \\
Diabetes (yes/no) & 10.05 & $2.1-46.9$ & $\mathbf{0 . 0 0 3}$ \\
Cardiopathy (yes/no) & 3.7 & $1.05-13.4$ & $\mathbf{0 . 0 4}$ \\
Peripheral vasc. dis. (yes/no) & 9.7 & $2.5-37.4$ & $\mathbf{0 . 0 0 1}$ \\
\hline Mg (mg/dL) & 0.4 & $0.08-2.5$ & n.s. \\
Calcium (mg/dL) & 0.8 & $0.31-2.16$ & n.s. \\
Phosphate (mg/dL) & 1.26 & $0.72-2.2$ & n.s. \\
PTH (pg/mL) & 1.001 & $0.99-1.002$ & n.s. \\
25 OH vitamin D (ng/mL) & 0.76 & $0.22-2.6$ & n.s. \\
\hline Albumin $(\mathrm{g} / \mathrm{dL})$ & 0.12 & $0.04-0.39$ & $\mathbf{0 . 0 0 1}$ \\
Transferrin $(\mathrm{mg} / \mathrm{dL})$ & 0.98 & $0.97-0.99$ & $\mathbf{0 . 0 3}$ \\
Proteinuria (g/24h) & 1.17 & $0.99-1.01$ & 0.06 \\
CrC (mL/min) & 0.92 & $0.85-1.008$ & n.s. \\
Hemoglobin (g/dL) & 0.79 & $0.53-1.19$ & n.s. \\
CRP (mg/L) & 1.03 & $0.97-1.09$ & n.s. \\
\hline
\end{tabular}

pressure and volume control. Furthermore, we found an inverse correlation in the limit of significance between serum magnesium and the daily dose of loop diuretics. Thus, we could hypothesize that serum magnesium could be modified by the use of diuretics, and this could explain the lack of influence of serum magnesium levels on cardiovascular outcomes in our patients. Otherwise, as our follow-up period was shorter than in the Kanbay's study, we cannot rule out that magnesium concentration could have any influence on outcomes at longer follow-up periods.

According to other studies [23], serum magnesium levels were lower in our diabetic patients. Surprisingly, we did not find any relationship between serum magnesium and bone and mineral metabolism parameters. In vitro and in vivo studies have demonstrated that magnesium concentrations 
modulate PTH secretion in a similar manner to calcium $[24,25]$, and several authors have observed an inverse correlation between serum magnesium and PTH levels in dialysis patients $[26,27]$. However, other studies failed to show a correlation between serum magnesium and serum PTH levels in peritoneal dialysis patients [28]. Otherwise, many of the studies evaluating the association between PTH and magnesium are not controlled well enough or suffer from other methodological drawbacks to draw firm conclusions [11]. Independent of its effect on PTH levels, magnesium is a potent inhibitor of vascular calcification via multiple molecular mechanisms $[6-8,11]$. Unfortunately, data of vascular calcification were not analyzed in our patients. Magnesium also participates in the atherosclerotic process by its effect on endothelial function. It has been suggested that high magnesium level can improve endothelial function via its anti-inflammatory effect. This hypothesis is supported by recent studies in which magnesium intake was inversely associated with C-reactive protein concentration [29]. However, we did not find any significant relationship between serum magnesium and CRP levels in our patients. Serum magnesium also did not correlate with biochemical markers of cardiac disease such as NT-proBNP levels, and serum magnesium was not different in patients with or without cardiac disease at baseline.

\section{Conclusions}

Contrary to previous reports in the general population and in patients with CKD, the present study does not support that low serum magnesium level could influence on overall mortality or future cardiovascular events among patients with advanced CKD not yet on dialysis at short-term (one year) follow-up. As most of our patients used loop diuretics and an inverse correlation between serum magnesium and the daily dose of loop diuretics was found in our study, we could hypothesize that serum magnesium could be modified by the use of diuretics, and this could explain the lack of influence of serum magnesium levels on cardiovascular outcomes in our patients.

The small sample size and the relative short follow-up time of our study could have biased our findings. Thus, further studies are needed to confirm our results or, on the contrary, to support the results of other studies that suggest a detrimental effect of low serum magnesium on mortality or cardiovascular outcome in this population.

\section{Disclosure}

The results presented in this paper have not been published previously.

\section{Conflict of Interests}

The authors declare that they have no conflict of interests.

\section{References}

[1] S. G. Massry and M. S. Seelig, "Hypomagnesemia and hypermagnesemia," Clinical Nephrology, vol. 7, no. 4, pp. 147-153, 1977.

[2] B. M. Altura and B. T. Altura, "New perspectives on the role of magnesium in the pathophysiology of the cardiovascular system. I. Clinical aspects," Magnesium, vol. 4, no. 5-6, pp. 226244, 1985.

[3] M. Shechter, C. N. B. Merz, M. Paul-Labrador et al., "Oral magnesium supplementation inhibits platelet-dependent thrombosis in patients with coronary artery disease," American Journal of Cardiology, vol. 84, no. 2, pp. 152-156, 1999.

[4] A. Mazur, J. A. M. Maier, E. Rock, E. Gueux, W. Nowacki, and Y. Rayssiguier, "Magnesium and the inflammatory response: potential physiopathological implications," Archives of Biochemistry and Biophysics, vol. 458, no. 1, pp. 48-56, 2007.

[5] D. Zheng, R. N. Upton, G. L. Ludbrook, and A. Martinez, "Acute cardiovascular effects of magnesium and their relationship to systemic and myocardial magnesium concentrations after short infusion in awake sheep," Journal of Pharmacology and Experimental Therapeutics, vol. 297, no. 3, pp. 1176-1183, 2001.

[6] A. Zhang, T. P. O. Cheng, and B. M. Altura, "Magnesium regulates intracellular free ionized calcium concentration and cell geometry in vascular smooth muscle cells," Biochimica et Biophysica Acta, vol. 1134, no. 1, pp. 25-29, 1992.

[7] F. Kircelli, M. E. Peter, E. Sevinc et al., "Magnesium reduces calcification in bovine vascular smooth muscle cells in a dosedependent manner," Nephrology Dialysis Transplantation, vol. 27, no. 2, pp. 514-521, 2012.

[8] S. Salem, H. Bruck, F. H. Bahlmann et al., "Relationship between magnesium and clinical biomarkers on inhibition of vascular calcification," American Journal of Nephrology, vol. 35, no. 1, pp. 31-39, 2012.

[9] F. Liao, A. R. Folsom, and F. L. Brancati, "Is low magnesium concentration a risk factor for coronary heart disease? The Atherosclerosis Risk in Communities (ARIC) Study," American Heart Journal, vol. 136, no. 3, pp. 480-490, 1998.

[10] J. Ma, A. R. Folsom, S. L. Melnick et al., "Associations of serum and dietary magnesium with cardiovascular disease, hypertension, diabetes, insulin, and carotid arterial wall thickness: the aric study," Journal of Clinical Epidemiology, vol. 48, no. 7, pp. 927-940, 1995.

[11] J. Cunningham, M. Rodríguez, P. Messa et al., "Magnesium in chronic kidney disease stage 3 and 4 and in dialysis patients," Clinical Kidney Journal, vol. 5, supplement 1, pp. i39-i51, 2012.

[12] A. C. Truttmann, R. Faraone, R. O. von Vigier, J. M. Nuoffer, R. Pfister, and M. G. Bianchetti, "Maintenance hemodialysis and circulating ionized magnesium," Nephron, vol. 92, no. 3, pp. 616621, 2002.

[13] J. Kelber, E. Slatopolsky, and J. A. Delmez, "Acute effects of different concentrations of dialysate magnesium during highefficiency dialysis," American Journal of Kidney Diseases, vol. 24, no. 3, pp. 453-460, 1994.

[14] A. Scholze, V. Jankowski, L. Henning et al., "Phenylacetic acid and arterial vascular properties in patients with chronic kidney disease stage 5 on hemodialysis therapy," Nephron Clinical Practice, vol. 107, no. 1, pp. cl-c6, 2007.

[15] W. G. Goodman, J. Goldin, B. D. Kuizon et al., "Coronary-artery calcification in young adults with end-stage renal disease who are undergoing dialysis," The New England Journal of Medicine, vol. 342, no. 20, pp. 1478-1483, 2000. 
[16] J. Blacher, A. P. Guerin, B. Pannier, S. J. Marchais, and G. M. London, "Arterial calcifications, arterial stiffness, and cardiovascular risk in end-stage renal disease," Hypertension, vol. 38, no. 4, pp. 938-942, 2001.

[17] I. Tzanakis, K. Virvidakis, A. Tsomi et al., "Intra- and extracellular magnesium levels and atheromatosis in haemodialysis patients," Magnesium Research, vol. 17, no. 2, pp. 102-108, 2004.

[18] F. Turgut, M. Kanbay, M. R. Metin, E. Uz, A. Akcay, and A. Covic, "Magnesium supplementation helps to improve carotid intima media thickness in patients on hemodialysis," International Urology and Nephrology, vol. 40, no. 4, pp. 1075-1082, 2008.

[19] E. Ishimura, S. Okuno, T. Yamakawa, M. Inaba, and Y. Nishizawa, "Serum magnesium concentration is a significant predictor of mortality in maintenance hemodialysis patients," Magnesium Research, vol. 20, no. 4, pp. 237-244, 2007.

[20] I. Tzanakis, A. Pras, D. Kounali et al., "Mitral annular calcifications in haemodialysis patients: a possible protective role of magnesium," Nephrology Dialysis Transplantation, vol. 12, no. 9, pp. 2036-2037, 1997.

[21] B. M. Altura and B. T. Altura, "Magnesium and cardiovascular biology: an important link between cardiovascular risk factors and atherogenesis," Cellular \& Cellular Biology, vol. 41, no. 5, pp. 347-359, 1995.

[22] M. Kanbay, M. I. Yilmaz, M. Apetrii et al., "Relationship between serum magnesium levels and cardiovascular events in chronic kidney disease patients," American Journal of Nephrology, vol. 36, no. 3, pp. 228-237, 2012.

[23] K. Dewitte, A. Dhondt, M. Giri et al., "Differences in serum ionized and total magnesium values during chronic renal failure between nondiabetic and diabetic patients: a cross-sectional study," Diabetes Care, vol. 27, no. 10, pp. 2503-2505, 2004.

[24] S. G. Massry, J. W. Coburn, and C. R. Kleeman, "Evidence for suppression of parathyroid gland activity by hypermagnesemia," Journal of Clinical Investigation, vol. 49, no. 9, pp. 1619$1629,1970$.

[25] I. N. Cholst, S. F. Steinberg, P. J. Tropper, H. E. Fox, G. V. Segre, and J. P. Bilezikian, "The influence of hypermagnesemia on serum calcium and parathyroid hormone levels in human subjects," The New England Journal of Medicine, vol. 310, no. 19, pp. 1221-1225, 1984.

[26] M. Wei, K. Esbaei, J. M. Bargman, and D. G. Oreopoulos, "Inverse correlation between serum magnesium and parathyroid hormone in peritoneal dialysis patients: a contributing factor to adynamic bone disease?" International Urology and Nephrology, vol. 38, no. 2, pp. 317-322, 2006.

[27] J. F. Navarro, C. Mora, A. Jiménez, A. Torres, M. Macía, and J. García, "Relationship between serum magnesium and parathyroid hormone levels in hemodialysis patients," American Journal of Kidney Diseases, vol. 34, no. 1, pp. 43-48, 1999.

[28] M. S. Cho, K. S. Lee, Y. K. Lee et al., "Relationship between the serum parathyroid hormone and magnesium levels in continuous ambulatory peritoneal dialysis (CAPD) patients using low-magnesium peritoneal dialysate," Korean Journal of Internal Medicine, vol. 17, no. 2, pp. 114-121, 2002.

[29] D. E. King, "Inflammation and elevation of C-reactive protein: does magnesium play a key role?" Magnesium Research, vol. 22, no. 2, pp. 57-59, 2009. 


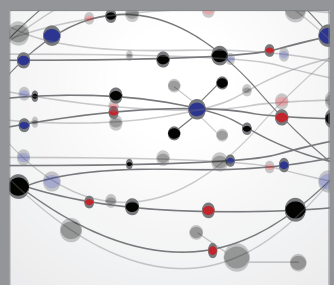

The Scientific World Journal
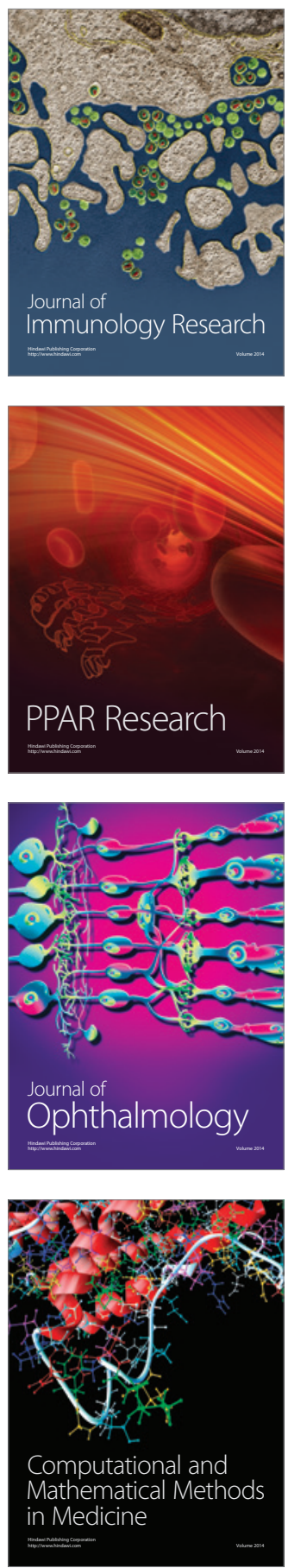

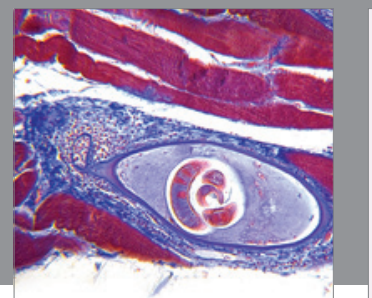

Gastroenterology

Research and Practice
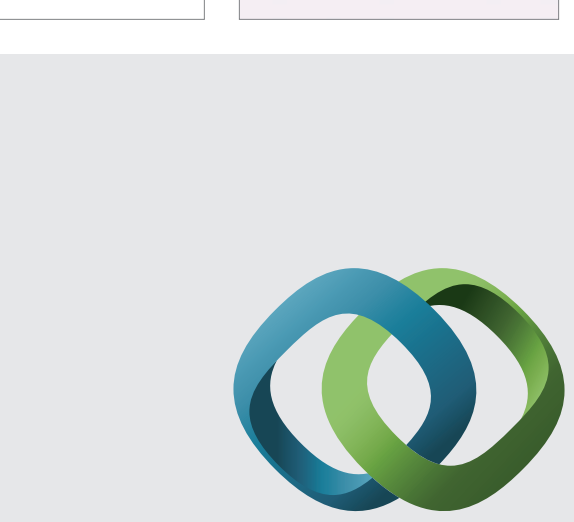

\section{Hindawi}

Submit your manuscripts at

http://www.hindawi.com
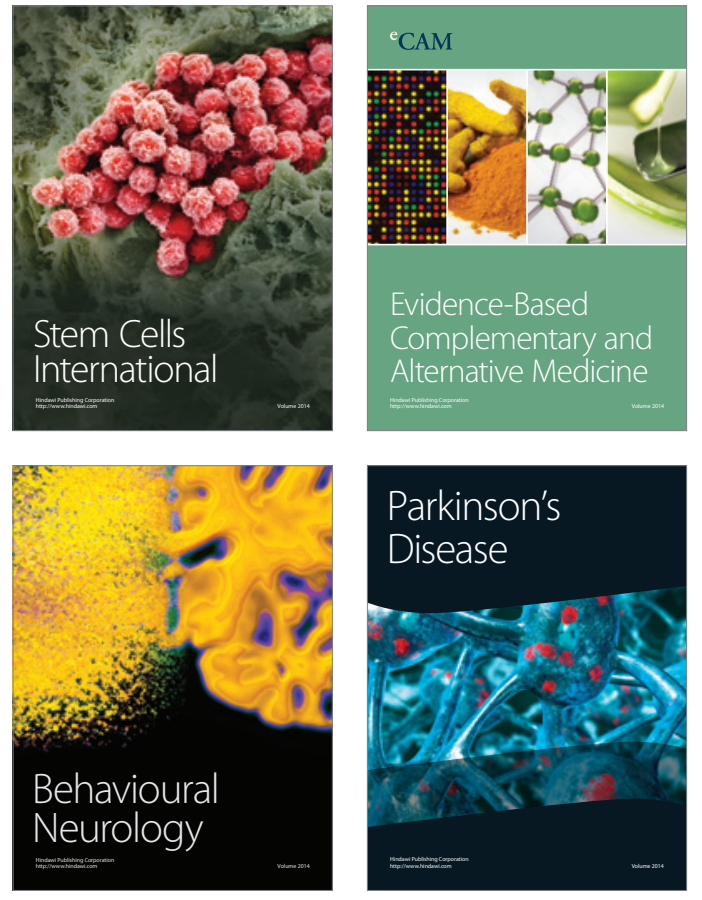
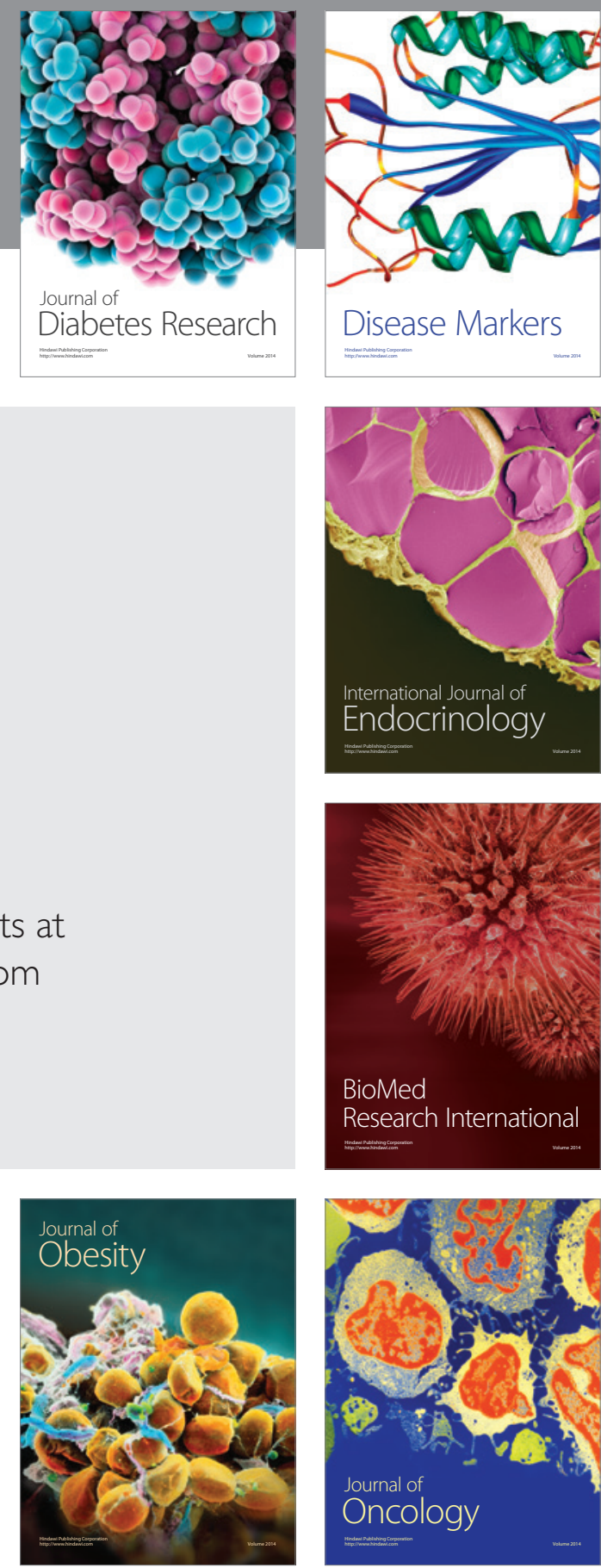

Disease Markers
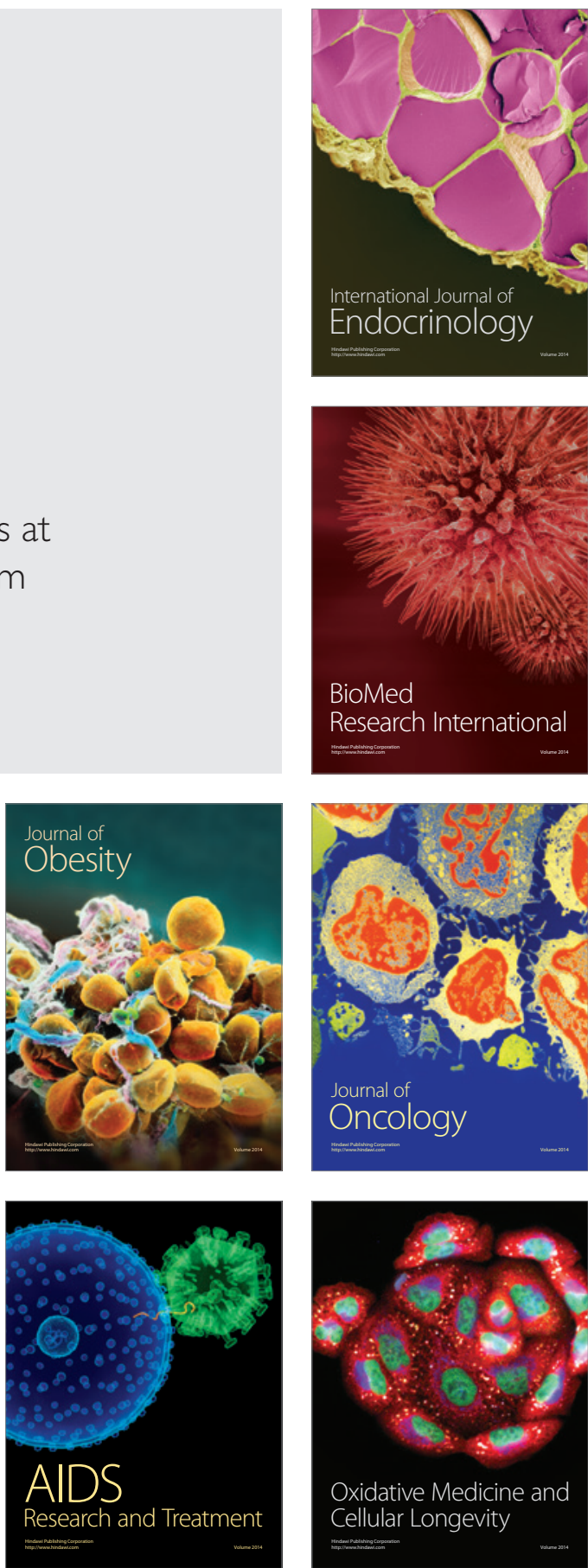